\title{
Violencia en espacios digitales en México. Una mirada desde la pandemia de Covid-19
}

\section{Violence in digital spaces in Mexico. A perspective from the Covid-19 pandemic}

\section{Karina Nohemí Martínez Meza', Arturo Miguel Chípuli Castillo²}

1. Doctora en Ciencias de Gobierno y Política - Benemérita Universidad Autónoma de Puebla (BUAP), Maestra en Derecho con terminal en Ciencias Penales (BuAp), Profesora-Investigadora del Colegio de Veracruz, México. Es miembro del Sistema Nacional de Investigadores (sIN), con distinción de candidata, por el Consejo de Ciencia y Tecnología (conAcyT), México. https:// orcid.org/0000-0003-2257-1480. karina.n.mtz@gmail.com

2. Doctor en Derecho (Universidad de Xalapa), Maestro en Derecho Constitucional y Juicio de Amparo (Universidad de Xalapa), Maestro en Derechos Humanos y Democracia (Facultad Latinoamericana de Ciencias Sociales, flacso Sede México), Profesor -Investigador de tiempo completo en el Instituto de Investigaciones Jurídicas (IIJ) de la Universidad Veracruzana (uv).https://orcid.org/0000-0001-8808-3311. achipuli@uv.mx

Resumen: El objetivo de este artículo es identificar los elementos más importantes de la violencia de género en los espacios virtuales. Lo anterior, a través de los actores, procesos y dinámicas. Igualmente, analizar de qué manera el factor contextual de la pandemia de Covid-19 se vincula con este tipo de violencia en México. Es una investigación cualitativa, un estudio de caso, a partir del método documental. Algunos de los hallazgos son: a) Se habla de un fenómeno social y complejo que necesita de nuevas metodologías 
vinculadas con los avances de la tecnología, información y conocimiento; b) Existen nuevos actores visibles e invisibles, nuevos procesos, tendencias, patrones, códigos, símbolos e interpretaciones; c) Puede haber una relación entre el confinamiento, la violencia de género en espacios virtuales y los derechos humanos. d) El factor contextual puede influir en el desarrollo de este fenómeno social. Se concluye que la pandemia del Covid-19, sólo ha visibilizado aquello que ha existido siempre: la poca claridad respecto a la garantía del derecho a una vida libre de violencia en México.

Palabras claves: Violencia, Violencia digital, Espacios virtuales, Pandemia Covid-19.

Abstract: The objective of this article is to identify the most important elements of gender violence in virtual spaces. The above, through the actors, processes and dynamics. Likewise, analyze how the contextual factor of the Covid-19 pandemic is linked to this type of violence in Mexico. It is a qualitative research, a case study, based on the documentary method. Some of the findings are: a) there is talk of a social and complex, which requires new methodologies linked to advances in technology, information and knowledge; b) There are new visible and invisible actors, new processes, trends, patterns, codes, symbols and interpretations; c) There may be a relationship between confinement, gender violence in virtual spaces and human rights. d) The contextual factor can influence the development of this social phenomenon. It is concluded that the Covid-19 pandemic has only made visible what has always existed: the lack of clarity about the guarantee of the right to a life free of violence in Mexico.

Keywords: Violence; Digital violence; Virtual spaces; Covid-19 pandemic.

\section{Introducción}

La aplicación o adopción de los dispositivos tecnológicos, de comunicación o información, se ha institucionalizado no sólo en lo público, sino también en las esferas de lo privado y lo íntimo; y sin duda, son parte de los cambios y transformaciones de la vida cotidiana del Siglo xxI, ya sea como un medio 
o como un fin. Así, por ejemplo, encontramos que las relaciones de poder y dominio se desarrollan con esquemas más flexibles y horizontales; que las interacciones mediáticas pueden generarse y reproducirse en un nuevo espacio virtual o ciberespacio por medio del cual se reduce tiempo; se mejora la velocidad de intercambios de datos y de comunicación; se transforma el estado de movilidad social; la apertura al conocimiento es de manera horizontal, abierta y global; dando con esto una mayor libertad en la toma de decisión de los usuarios con respecto a los espacios que no se consideran virtuales.

Los dispositivos tecnológicos de información y comunicación son medios que proporcionan herramientas para el conocimiento y socialización de las personas, al mismo tiempo, suponen nuevos riesgos antes inexistentes o con diferentes tonalidades y matices de ejecución (estos últimos comparados con los tipos tradicionales de violencia psicológica, sexual, económica y patrimonial; y simbólica), pues utilizan recursos más sofisticados y con mayores capacidades técnicas. En el espacio virtual encontramos acciones, conductas, omisiones que producen un efecto negativo (psíquico, físico, moral o simbólico) desde la angustia, miedo o enojo hasta un daño o sufrimiento físico, incluso la muerte.

La violencia de género también puede analizarse a la luz de este contexto y promoverse por la protección que le ofrece el anonimato al agresor, por la facilidad de viralización y el poder de daño consecuente y trascendente. De igual modo, puede generar la violación de los derechos humanos porque es una forma más de violencia y discriminación que se manifiesta en acciones ejercidas contra las mujeres por el solo hecho de serlo.

En marzo de 2020, una situación mundial de salud, cambió la manera de arrojar luz y entender a este tipo de fenómenos sociales, pues la vida cotidiana y la sociabilidad dieron un giro de 180 grados. Los protagonistas ya no eran los delincuentes o las víctimas, el incremento de la violencia o delincuencia, los riegos, las amenazas, el miedo, la inseguridad o la impunidad. Los gobiernos se declararon en estado de emergencia y con ello, la restricción de ciertos derechos humanos ${ }^{1}$ (como el de movilidad y tránsito) ante una enfermedad

1. Sin duda, la pandemia ha significado una amenaza y un riesgo para la salud y la vida, y es un elemento o factor que ha impactado en la toma de decisión y en la respuesta inmediata de los gobiernos, 
que no tiene vacuna. La preocupación alcanzó niveles inusitados debido a la facilidad de contagio y propagación, situación que ha motivado profundos cambios en la manera en que se desarrollan las actividades cotidianas de las sociedades contemporáneas. En ese momento, todo giró en razón del mundo digital: cibernautas, usuarios, conectados, sistemas, redes, comunidades virtuales, industrias tecnológicas y de información, consumo y servicios, gobierno electrónico, y más.

Es por ello, que, el objetivo de este trabajo es identificar y analizar los elementos más importantes de la violencia de género que se desarrolla en los diversos espacios virtuales o digitales. Lo anterior, a través de los actores, procesos y dinámicas que se desenvuelven en el fenómeno social. Igualmente, analizar de qué manera el factor contextual de la pandemia de Covid-19 se vincula con este tipo de violencia en México. Es una investigación cualitativa, un estudio de caso, a partir del método documental donde se recolectó y revisó

principalmente, en la protección y garantía de todo el conjunto de derechos humanos. Es así que, el 10 de abril del 2020 la Comisión Interamericana de Derechos Humanos adoptó la Resolución No. 1/2020 “Pandemia y Derechos Humanos en las Américas". En tal resolución, la Comisión hizo énfasis en la necesidad de adoptar estrategias para prevenir, atender y contener el virus sobre la base de los derechos humanos. Esto en razón de que, la rápida propagación orilló a diversos gobiernos a adoptar acciones extraordinarias, en el marco de la declaración de Estados de excepción y emergencia. Así, por ejemplo, en el caso mexicano, a nivel subnacional, la entidad federativa de Puebla, implementó la medida temporal “Hoy No Circula”, para la reducción de la movilidad de las personas, mediante la restricción de la circulación o tránsito vehicular entre la población en el Territorio del Estado de Puebla (Decreto publicado el 8 de mayo de 2020 por el Periódico Oficial del Estado de Puebla). En contraste con lo señalado por la Secretaría de Gobernación, que declaró que la emergencia sanitaria no representaba el establecimiento de un estado de excepción y suspensión de garantías. La relevancia de implementar el enfoque de derechos humanos, tiene una importancia fundamental en contextos excepcionales, tales como una situación de pandemia, donde los Estados observan un alto grado de discrecionalidad para la implementación de medidas inusuales, heterogéneas y muchas veces violatorias de derechos humanos, principalmente en regiones con amplias brechas de desigualdad, pobreza, corrupción, violencia e impunidad (CHÍPULI, 2020). 
bibliografía especializa y datos oficiales y públicos. En los siguientes aparatados se estudiarán los aspectos generales de la violencia de género, su desarrollo en los espacios virtuales o digitales, en particular, el caso mexicano y la vinculación con la situación de la pandemia Covid-19.

\section{La Violencia de Género. Aspectos Generales}

La violencia de género representa un concepto sumamente discutido, debido principalmente, a los múltiples elementos que le integran, así como el carácter uni o bi-direccional respecto de quien la ejerce, además de las modalidades bajo las cuales se realiza. En este sentido, se abordará a continuación, y de forma general, algunos conceptos que son relevantes para el entendimiento del mismo.

En primer lugar, el término "género" refiere una forma primaria de relaciones significantes de poder, o mejor dicho, que el género es el campo primario dentro del cual o por medio del cual se articula el poder. Establecidos como conjunto de referentes, los conceptos de género estructuran la percepción y la organización, concreta y simbólica, de toda la vida social. Hasta el punto en que esas referencias establecen distribuciones de poder (control diferencial sobre los recursos materiales y simbólicos, o acceso a los mismos), el género se implica en la concepción y construcción del poder" (scotт, 1990). Como afirman Fries y Lacrampette (2013, p. 62), el término "género" ha variado en alcance y contenido a lo largo de su estudio y aplicación por las ciencias sociales. Dado que el estatus de la mujer no se debe a un factor único, y de lo cual se han desarrollado diversas teorías sobre el género que enfatizan distintos aspectos de este, sin perjuicio de lo cual es posible afirmar que la mayoría de ellas "coinciden en que a partir de una importancia exagerada a las diferencias biológicas - y de una invisibilización de las grandes similitudes - se construyen las diferencias/ desigualdades constitutivas de cada sexo. Esta asignación de características, comportamientos y roles tiene elementos descriptivos y normativos a la vez. El concepto de género, entonces, permitirá explicar que la subordinación de las mujeres en las sociedades se relaciona con dos elementos: uno de diferenciación y otro de poder o jerarquía. El primero corresponde a la construcción 
cultural de las diferencias entre lo femenino y masculino y la atribución de estas características a mujeres y hombres desde su nacimiento, definiendo así el estatus que cada uno detentará en la sociedad y los roles que desempeñarán en la vida pública y privada. El segundo elemento, por su parte, expresa que las características diferenciadas que se atribuyen a hombres y mujeres constituyen una jerarquía en que lo masculino resulta favorecido y socialmente valorado, en detrimento de lo que se construye y señala como femenino. ${ }^{2}$

En segundo lugar, los estereotipos, refieren a todas aquellas características, actitudes y roles que estructuralmente en una sociedad son atribuidas a las personas, y que tienen sus bases en un proceso de simplificación para el entendimiento y aproximación del mundo. Los estereotipos, bajo el supuesto anterior, refieren a procesos que son comunes a todas las personas en una sociedad. Sin embargo, lo problemático de estos surge cuando a dichas características, actitudes y roles, se les adjudican consecuencias jurídicas, sociales, políticas, que generan una desestimación o subordinación $(\mathrm{scjN}, 2013$, p.4849). La violencia, en tercer lugar, remite a una concepción sumamente amplia y con una carga valorativa comúnmente negativa. Existen diversas nociones respeto de la misma: la noción restringida, que refiere a la violencia física; la noción medianamente restringida, limitada a la violencia física pero que, además, equipara a esta con las amenazas; la noción moderada que contempla la violencia física, amenazas y otras formas de violencia verbal; y la noción amplia, que abarca todo lo que produce daños físicos, psicológicos y/o económicos (POGGI, 2019, p. 290).

La "Violencia de género", por su parte, da cuenta de "las estructuras simbólicas que justifican y naturalizan la violencia” (MAFFíA, 2012, p. 5). Se trata,

2. Resulta interesante advertir que en México, el máximo tribunal del país ha definido el género, en su protocolo para juzgar con perspectiva de género, como los atributos que, histórica, social, cultural y geográficamente, se le han asignado a los hombres y a las mujeres, es decir, se utilizan de forma general para referirse a las características que social y culturalmente se han identificado como "masculinas" o"femeninas, las cuales pueden abarcar desde funciones que históricamente se han asignado a uno u otro sexo, las actitudes que generalmente se les imputan, hasta las formas de vestir, caminar, hablar, pensar, sentir y relacionarse (SCJN, 2014, p.13). 
de acuerdo con la definición más aceptada (propuesta por la onU en 1995) de "todo acto de violencia sexista que tiene como resultado posible o real un daño físico, sexual o psíquico, incluidas las amenazas, la coerción o la privación arbitraria de libertad, ya sea que ocurra en la vida pública o en la privada" (ExPósito, 2011, p. 20). Al respecto, la autora antes citada refiere que la violencia de género actualmente se configura como una “... conducta instrumental que introduce desigualdad en una relación interpersonal o mantiene una desigualdad subyacente y estructural....violencia y el género se convierten en un binomio inseparable, ya que la primera se usa como mecanismo para conseguir un plus de presencia o influencia respecto a lo segundo" (EXPósıтo, 2011, p. 20). Como puede apreciarse, la violencia de género refiere una expresión que busca capturar la violencia que se produce como resultado de expectativas normativas sobre los roles asociados a cada género, junto con las relaciones desiguales de poder entre los dos géneros, en una sociedad especifica (POGGI, 2019, p. 294). Al respecto, Tamara Adrian (2015, p. 17) refiere:

"La violencia basada en género es una categoría mucho más amplia que la violencia contra la mujer, tanto en lo que se refiere a su naturaleza como a sus características. En efecto, el género, entendido como una construcción social que interpreta culturalmente las manifestaciones estereotipadamente asociadas al sexo, se constituye, en sí mismo, en una especie de prisión en la que todos los individuos son -al mismo tiempo- prisioneros y guardianes. En una especie de síndrome de Estocolmo colectivo, los prisioneros se identifican con los guardianes a los fines de ejercer el poder de control sobre cualquier comportamiento disidente de dicha estructura. El género, es así, la base misma de perpetuación del patriarcado, y se instituye en una superestructura de dominación que se manifiesta en la creación e imposición normativa de constructos sociales que establecen patrones y modos de conducta separados entre hombres y mujeres -y aún entre ellos- dependiendo de su edad, fuerza física, propensión a la violencia, orientación sexual,identidad de género, y otra serie de variables íntimamente relacionadas con el género. Siendo así, dichas estructuras desbordan por mucho las solas relaciones entre hombres y mujeres". 
No obstante, lo anterior, si bien las violaciones a derechos humanos afectan tanto a hombres como a mujeres, su impacto y su carácter varían de acuerdo con el sexo de la víctima. De ahí que, podamos advertir que de forma usual se refiera que la violencia de género se vincula principalmente con la discriminación, abusos e infravaloración de la mujer. Esto en razón de la asimetría existente en las relaciones de poder entre valores y mujeres, las cuales perpetúan la subordinación y desvaloración de lo femenino frente a lo masculino (RICO, 1996, p.8).

En las últimas décadas se ha ido reconociendo cada vez más en el ámbito internacional que la violencia de género es un grave problema, no sólo para las mujeres sino también para el logro de la igualdad, el desarrollo y la paz (NAciones unidas, 1986). En el ámbito interamericano, la Convención de Belém do Pará, significó un gran esfuerzo para reconocer el derecho de las mujeres a vivir una vida libre de violencia. Dando la pauta para la adopción de leyes y políticas sobre prevención, erradicación y sanción de la violencia contra las mujeres en los Estados Parte de la Convención, formulación de planes nacionales, organización de campañas e implementación de protocolos y de servicios de atención, entre otras iniciativas; y ha sido un aporte significativo al fortalecimiento del Sistema Interamericano de Derechos Humanos.

\subsection{La Violencia de Género en México}

Si bien en las líneas que anteceden hemos referido que la violencia de género no se limita a una relación unidireccional entre mujer y hombre, a nivel global, impera una ominosa tendencia que enfatiza el alto grado de violencia que viven mujeres y niñas. Sobre todo, en sistemas sociales donde existen jerarquías formales de privilegios, como los sistemas patriarcales, donde se integra un claro mensaje que permite que los poderosos se hallan en derecho de dominar a los débiles, y que la violencia es una herramienta válida y necesaria para ello (EXPósıтo, 2011, p. 22). Al respecto, es menester enfatizar lo siguiente:

La violencia contra la mujer constituye así la forma más conocida de violencia basada en estructuras de género. Pero no es la única. Sin embargo, es aquella que eventualmente ha recibido la mayor atención. Ello, por una parte, 
porque el discurso feminista originario de reivindicación del derecho efectivo a la igualdad legal, social y cultural de la mujer enfocó parte de su acción hacia la visibilización de aquellas formas de violencia que se instituían en mecanismos de control o policía de cualquier comportamiento o expresión por parte de la mujer que no se amoldase a los patrones subordinados de conducta esperados en ella por el constructo tradicional. Eso incluye, entre otros, -en el ámbito de las situaciones y relaciones de producción- la modificación de las condiciones de trabajo, estudio y acceso a los medios de producción, y -en el ámbito de las situaciones y relaciones reproductivas- la modificación de los roles y características de dicha función, incluyendo la crianza de los hijos y las labores del hogar. Pero, por otra parte, porque ese tipo de violencia basada en género ejercida por el hombre contra la mujer ha pasado de ser, por su motivación, de una acción aceptable socialmente a una forma particularmente odiosa de dominación por medio de la violencia, inadmisible de acuerdo con el derecho internacional de los derechos humanos en el mundo contemporáneo. Es decir, que la violencia que fue justificada históricamente por la "superioridad" masculina, se condena hoy como un hecho inadmisible. Ambos hechos constituyen un hito desde el punto de vista de la evolución de los derechos de la mujer. Aunque puede haber habido una transformación mayor en el ámbito de las situaciones y relaciones de producción, que en el de las situaciones y relaciones de reproducción, donde los estereotipos de género han sido más duros de vencer (ADRIÁN, 2015, p. 19).

Derivado de lo antes mencionado, es posible advertir que la presión social, y sobre todo el ejercicio de la protesta y la movilización de los colectivos feministas en México han sido fundamentales para que las instancias nacionales y supranacionales realizaran un reconocimiento progresivo de la violencia de género. El caso de México es paradigmático, pues la violencia feminicida, sobre todo en el periodo comprendido entre 1993 y 2013, se extendió de manera alarmante a todo el territorio del país (ANSOlabehere Y valle, 2017, p. 38). Esta situación puso en evidencia que tanto la sociedad, como el Estado, eran participes de un reconocimiento desigual de los derechos humanos de las mujeres. El machismo y la misoginia, culturalmente arraigados en la sociedad, en suma con la violencia institucional arraigada en el sistema de justicia mexicano 
(impunidad en la investigación y sanción de los feminicidios, discriminación en la impartición de justicia y en las averiguaciones de los delitos y los peritajes, procesos con una mirada profundamente misógina) han sido elementos constitutivos de una situación de opresión hacia la mujer, quien ha sido sometida a un contexto de violencia generalizada. Como afirma Marcela Legarde, México representa un país con una situación excepcional de violencia contra mujeres, niñas y adolescentes, donde cada día son asesinadas en promedio 4 de ellas; y donde la falta de una perspectiva de género de las autoridades impide la construcción de cifras confiables que den cuenta de la ominosa situación que prevalece en el país (LEGARDE, 2006, p. 218-224)

Los feminicidios en la franja fronteriza se constituyeron como verdaderos actos de violencia y muerte resignificada, fundada en estructuras tradicionales de dominación masculina, en la cual los estereotipos de femineidad y masculinidad se encuentran bajo una fuerte carga patriarcal (RAVELo, 2005, p. 152-155). Las instituciones públicas y las normas no fueron ajenas a tales vicios. El sistema patriarcal inserto en las instituciones públicas se mostró renuente a concesiones que dieran paso a la superación de las barreras sociales y estructurales de inclusión de la mujer, lo cual, aunado a una fuerte impunidad, represión, y contexto de violencia generalizada (caracterizada por desapariciones y asesinatos), llevó al gobierno a un proceso de invisibilización del problema (Ravelo, 2005, p. 156). La vulnerabilidad generada por el Estado hacia mujeres y niñas expresó una opresión de género institucionalizada, así como una desigualdad de relaciones entre lo masculino y lo femenino que derivó en manifestaciones de dominio, terror, exterminio social, hegemonía patriarcal, clase social e impunidad (FRAGoso, 2002, p. 282).

Si bien la presión internacional generada por las acciones de "avergonzamiento" contra México fue alta y persistente, y ocasionó una apertura política a la búsqueda de soluciones, motivando al gobierno mexicano a adoptar un discurso de DH. En este contexto, y conforme se fue acumulando la presión transnacional, el gobierno federal se fue involucrando y desarrollando un discurso de "compromiso" con los derechos de las mujeres, y con la investigación de algunos casos y el castigo de los responsables. Conforme la presión 
aumentaba y se acumulaba, los gobiernos federal y local poco a poco fueron abandonando su discurso de negación, y mediante una práctica creciente de reformas y de labor legislativa logró institucionalizar la figura del feminicidio, y el derecho humano de las mujeres a una vida libre de violencia, esto a través de una ley marco: la Ley General de Acceso de las Mujeres a una Vida Libre de Violencia (LGAMVLV). Esta respuesta institucional constituyó un importante avance en términos de las reivindicaciones de la mujer ante contextos de opresión, desigualdad estructural y patriarcado legal, institucional y cultural, muy de la mano de algunas exigencias que el Derecho Internacional de los Derechos Humanos (DIDH), y ONG's nacionales e internacionales habían exigido de manera puntual (LAGARDE, 2006, p. 217-221).

Pese a lo anterior, en México se sigue observando un clima de violencia contra la mujer, lo cual demuestra la falta de compromiso real en las acciones de política pública. A modo de ejemplo podemos señalar los siguientes datos. De acuerdo con onu Mujeres (2018) el 41.3\% de las mujeres en México han sido víctimas de violencia sexual en algún momento de sus vidas y el 66.8\% de las agresiones en contra de mujeres ocurridas en la calle son de tipo sexual.

De acuerdo con el Atlas de Género del Instituto Nacional de Estadística y Geografía (INEGI), la prevalencia de violencia total de las mujeres en México a lo largo de su vida es del $62.77 \%$. El indicador se encuentra construido a partir de los datos que proporcionan las mujeres mayores de 15 años que han sufrido al menos un incidente de violencia de cualquier tipo (física, sexual, emocional, económica o patrimonial) y en cualquier ámbito donde haya ocurrido y por parte de cualquier agresor. Conforme al citado estudio, en México la violencia de género se distribuye de la siguiente forma: 
Tabla 1: Prevalencia de violencia total contra las mujeres de 15 años y más a lo largo de su vida.

\begin{tabular}{|c|c|}
\hline Entidad & Mujeres \\
\hline Nacional & 62.77 \\
\hline Aguascalientes & 63.12 \\
\hline Baja California & 66.22 \\
\hline Baja California Sur & 55.92 \\
\hline Campeche & 59.06 \\
\hline Coahuila de Zaragoza & 58.60 \\
\hline Colima & 64.82 \\
\hline Chiapas & 43.53 \\
\hline Chihuahua & 68.76 \\
\hline Ciudad de México & 72.15 \\
\hline Durango & 55.78 \\
\hline Guanajuato & 56.24 \\
\hline Guerrero & 54.05 \\
\hline Hidalgo & 54.78 \\
\hline Jalisco & 64.49 \\
\hline México & 73.42 \\
\hline Michoacán de Ocampo & 59.64 \\
\hline Morelos & 63.61 \\
\hline Nayarit & 67.36 \\
\hline Nuevo León & 62.39 \\
\hline Oaxaca & 55.65 \\
\hline Puebla & 62.83 \\
\hline Querétaro & 60.43 \\
\hline Quintana Roo & 63.56 \\
\hline San Luis Potosí & 59.57 \\
\hline Sinaloa & 56.52 \\
\hline Sonora & 68.10 \\
\hline Tabasco & 55.66 \\
\hline
\end{tabular}




\begin{tabular}{|c|c|}
\hline Entidad & Mujeres \\
\hline Tamaulipas & 56.95 \\
\hline Tlaxcala & 61.92 \\
\hline Veracruz de Ignacio de la Llave & 62.01 \\
\hline Yucatán & 61.49 \\
\hline Zacatecas & 57.90 \\
\hline
\end{tabular}

Fuente: Encuesta Nacional sobre la Dinámica de las Relaciones en los Hogares (INEGI, 2011).

Aunado a lo anterior, México ocupa el primer lugar en impunidad en América Latina, lo que representa una grave crisis de acceso a la justicia. De acuerdo con el informe (In) Justicia Abierta (EQUis, 2019), la mayoría de los delitos no se denuncian: se estima que la cifra negra (ausencia de denuncias ciudadanas) es del 92\%, es decir, únicamente 1 de cada 10 delitos se denuncian. En el caso de las mujeres mexicanas (43 de cada 100) son víctimas de algún tipo de violencia, pero sólo 8 (5\%) denuncian. De los pocos delitos que se denuncian, sólo una minoría se judicializa, sin que esto garantice de ningún modo llegar a obtener una sentencia. Además, una sentencia tampoco es una garantía de protección y justicia para las mujeres, pues de las pocas sentencias que se han podido analizar (debido a la falta de transparencia de sentencias por parte de los poderes judiciales) se han advertido violaciones al derecho de acceso a la justicia de las mujeres. Estas violaciones han sido motivadas por razones de género, donde quien juzga es quien genera, justifica y perpetúa la violencia y la discriminación hacia las mujeres.

Llegado a este punto, es importante resaltar la participación y responsabilidad del Estado de prevenir y combatir la violencia, pues tiene el deber de reconocer y garantizar los derechos humanos de las mujeres en los niveles normativos y políticos. En México, se consagra y ratifica nuevamente esta obligación, a través de la reforma constitucional del 2011 en los artículos 1, 3, $11,15,18,29,33,89,97,102$ apartado B y 105. Por lo que, se presentará brevemente el concepto de perspectiva de género en las políticas públicas. 


\subsection{La Perspectiva de Género en las Políticas Públicas.}

La perspectiva de género cuestiona el paradigma de único "ser humano neutral", basado en el hombre blanco, heterosexual, adulto sin discapacidad, no indígena y en los roles determinados por dicho paradigma. Este enfoque permite mirar la diversidad de cuerpos y de proyectos de vida, así como la adecuación de normas y entornos en que se desenvuelven las personas, permitiendo detectar cuando se da un trato diferenciado ilegitimo, cuando es necesario o legitimo aplicar este, así como garantizar la aplicación del principio de igualdad (scjn, 2013, p. 64-69). Con base en lo anterior, en el Protocolo para Juzgar con Perspectiva de Género de la Suprema Corte de Justicia de la Nación (scjn, 2013, p. 64), se refiere que a través de esta perspectiva se deconstruye la falsa dicotomía basada en el cuerpo de las personas (mujeres/hombres), así como las consecuencias que se les han atribuido. Por lo tanto, representa una categoría de análisis que:

- Permite visibilizar la asignación social diferenciada de roles y tareas en virtud del sexo, género o preferencia/orientación sexual;

- Revela las diferencias en oportunidades y derechos que siguen a esta asignación;

- Evidencia las relaciones de poder originadas en estas diferencias;

- Se hace cargo de la vinculación que existe entre las cuestiones de género, la raza, la religión, la edad, las creencias políticas, etc.;

- Pregunta por los impactos diferenciados de las leyes y las políticas públicas basadas en estas asignaciones, diferencias y relaciones de poder, y

- Determina en qué casos un trato diferenciado es arbitrario y en qué casos es necesario (scjn, 2013, p. 64).

Es así, que, la perspectiva de género, representa un elemento transversal, vinculado con el enfoque de derechos humanos y el de las políticas públicas. Como su nombre lo indica, va más allá de la incorporación de estándares de derechos humanos al contenido de un programa de política pública, y comprende la necesidad de plantear su diseño, implementación y evaluación en términos de un enfoque que permita visualizar y atender las cuestiones arriba señaladas. 
Transversalizar el enfoque de género en la actuación gubernamental cambia no sólo la situación del sector público, sino que influye en las disposiciones y prácticas de la vida privada (LAmAs, s/f). El enfoque de género en política pública debe: "tomar en cuenta las diferencias entre los sexos en la generación del desarrollo y analizar en cada sociedad, las causas y los mecanismos institucionales y culturales que estructuran la desigualdad entre los sexos, así como elaborar políticas con estrategias para corregir los desequilibrios existentes" (ocde, 1998). Como afirma Teresa Incháustegui (1999), este enfoque es sin duda una orientación llamada a transformar de fondo los modelos de política pública predominantes en la mayoría de los países, además agrega:

“De acuerdo con este principio, la perspectiva de género en políticas públicas se traduciría en introducir la cuestión de la equidad entre los sexos no sólo en los métodos de análisis y de diagnóstico de la realidad social, que sirven de base para la elección y formulación de aquéllas, sino también en los procedimientos de evaluación, reprogramación y desempeño global de las mismas. Y lo que es más importante, en los mecanismos institucionales, formales e informales, que regulan la asignación de oportunidades y la distribución de cargas sociales entre los sexos, tanto en lo que toca a las estrategias y programas de política económica como a las políticas sociales, la política de derechos y la distribución de poder" (INCHÁustegui, 1999, p. 85-86).

De acuerdo con Lamas (S/F) la transversalización de la perspectiva o enfoque de género en las políticas públicas consiste en una estrategia doble: por un lado, reconociendo la diferenciación social, económica y política entre los sexos tomando en consideración las desigualdades de mujeres y hombres en todos los ámbitos de la sociedad, y por el otro lado, impulsar medidas específicas en los ámbitos en que, según los resultados de un diagnóstico de género, las mujeres no tienen acceso equitativo a recursos materiales y simbólicos.

En el logro de lo anterior, dos herramientas principales del enfoque de género son la auditoría de género y los presupuestos con perspectiva de género. La auditoría consiste en un análisis de la legislación y el presupuesto (incluyendo los subsidios, los impuestos y los proyectos sociales) para determinar los 
efectos que éstos provocan en la situación de ambos sexos. No se miden sólo los recursos destinados a las mujeres, ya que éstos constituyen una parte mínima del presupuesto total del Estado, sino también aquellos rubros que a primera vista no parecen relevantes para las mujeres. Como el presupuesto nacional es neutral, o sea, no distingue qué va para los hombres y qué para las mujeres, se suele suponer que el dinero los beneficia a ambos por igual. Sin embargo, no es así; todo lo que se hace, cada peso que se gasta, tiene un impacto diferente en cada sexo y esa variación se refiere al número y a la calidad de los servicios disponibles (LAMAs, S/F).

La violencia de género y su perspectiva de política pública, también puede analizarse a la luz del espacio virtual o digital, y promoverse por la protección que le ofrece el anonimato al agresor; por la facilidad de viralización y el poder de daño consecuente y trascendente. Y Sin duda, puede generar la violación de los derechos humanos porque es una forma más de violencia y discriminación que se manifiesta en acciones ejercidas contra las mujeres por el solo hecho de serlo. Es por ello, que a continuación estudiaremos la violencia de género en espacios digitales.

\section{Violencia de género en espacios digitales}

La aplicación o adopción de los dispositivos tecnológicos, de comunicación o información, se ha institucionalizado no sólo en lo público, sino también en las esferas de lo privado y lo íntimo, de manera acelerada desde las últimas décadas del Siglo xx y comienzo del Siglo xxi. Actualmente, forman parte de la vida cotidiana y de la socialización que establecemos diariamente. Estar conectado en la Era digital es sinónimo de nuevas oportunidades para aprender, comunicarse, innovar y desarrollar nuevas aptitudes, pero también significa estar expuesto a diversas agresiones que pueden ocasionar múltiples daños psicológicos con repercusiones de largo alcance y trascendencia. Nadie queda exento o libre de los riesgos y de la violencia que se produce y desarrolla en los espacios digitales. La violencia digital se genera principalmente en redes y se produce a través del uso cotidiano de las TIC, aunque también se incluyen las victimizaciones previas, simultáneas o consecuentes 
dentro y fuera del mundo virtual. Por medio de la conectividad digital, los delincuentes pueden mantenerse anónimos, reduciendo el riesgo de ser identificados y enjuiciados.

Entre las diversas manifestaciones de violencia digital, la literatura (PIETRAFESA, 2019; DONOso, 2018) y evidencia empírica (INFORME INSTITUCIONAL DEL OBSERVATORIO DE DERECHOS EN INTERNET, 2019; MÓDULO SOBRE CIBERACOSO, 2019) mencionan las siguientes: a) violencia sexual; b) sexting sin consentimiento; c) sextorsión; violencia online en pareja/ expareja; d) ciberacoso o ciberbullying; online grooming o ciberembaucamiento; e) exposición involuntaria a material sexual y/o violento; f) incitación a conductas dañinas; g) violencia viral; $h$ ) delito de producción y/o difusión de imágenes de abuso sexual infantil (pornografía infantil); i) corrupción de menores; j) trata de menores; $\mathrm{k}$ ) explotación sexual.

En los espacios digitales o virtuales, "se siguen reproduciendo y transmitiendo estereotipos y desigualdades de género, provenientes de esquemas tradicionales de discriminación, sobre los que se basa la violencia de género" (MÚÑIZ; CUESTA, 2015, p. 101). Esto es, se siguen reproduciendo los criterios y prácticas que ponen en desventaja a la mujer con respecto al varón, además de las conductas, acciones u omisiones que, "basada en una relación desigual de poder, afecta su vida, libertad, dignidad, integridad física, psicológica, sexual, económica o patrimonial, como así también su seguridad personal" (INFORME INSTITUCIONAL, 2019, p.4). La violencia de género en espacios virtuales, "afecta la reputación digital de las mujeres al lesionar alguno o varios de sus bienes y/o derechos digitales, como la reputación, la libertad, la existencia, el domicilio, la privacidad y la inclusión digital o afecta cualquier otro aspecto de su acceso y desenvolvimiento en el ámbito virtual" (p.4).

\section{Aspectos generales}

Si bien los dispositivos tecnológicos y las tecnologías de información y comunicación son recursos y medios que permiten ejercer y proteger los derechos de las mujeres, también pueden "favorecer su desvalorización y deslegitimación, pues el entorno virtual es un espejo o reflejo de las relaciones de poder en la 
Tabla 2: Tipos de violencia, modalidades y conductas de la violencia de género en espacios virtuales.

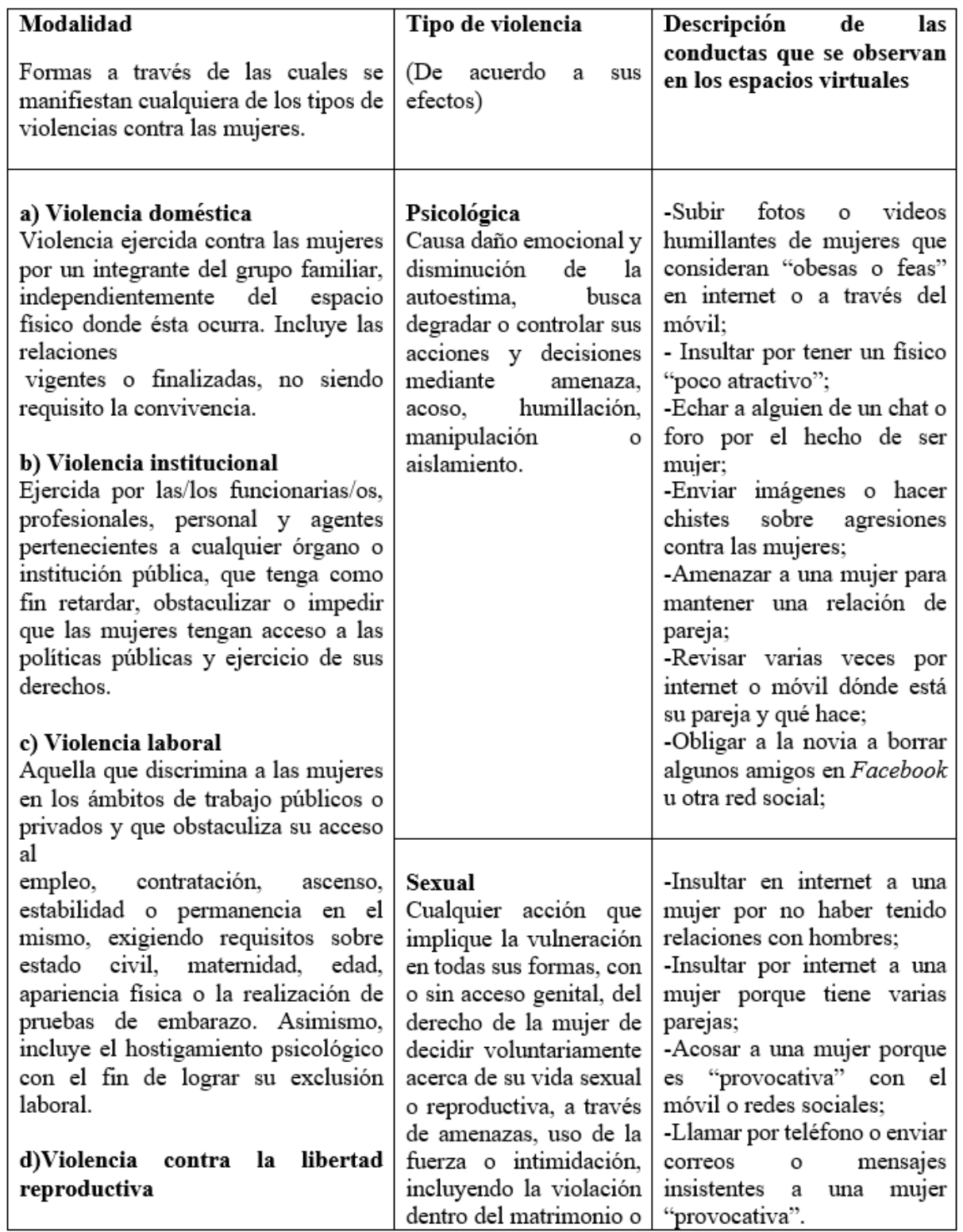


Violencia que vulnera el derecho de las mujeres a decidir libre y responsablemente sobre sus embarazos o el intervalo entre los nacimientos.

\section{e) Violencia obstétrica}

Aquella que ejerce el personal de salud sobre el cuerpo y los procesos reproductivos de las mujeres, expresada en un trato deshumanizado, un abuso de medicalización y patologización de los procesos naturales.

\section{f) Violencia mediática}

Publicación o difusión de mensajes e imágenes estereotipados a través de cualquier medio masivo de comunicación, que de manera directa o indirecta promueva la explotación de mujeres o sus imágenes, injurie, difame, discrimine, deshonre, humille o atente contra la dignidad de las mujeres; como así también la utilización de mujeres, adolescentes y niñas en mensajes e imágenes pornográficas, legitimando la desigualdad de trato o construya patrones socioculturales reproductores de la desigualdad o generadores de violencia contra las mujeres. de otras relaciones vinculares $\circ$ de parentesco, exista o no convivencia, así como la prostitución forzada, abuso sexual y trata de mujeres.

-Mostrar a la mujer simplemente como un objeto sexual en alguna página web; -Participar en una $W e b$ donde se puntúa el físico de las mujeres;

-Mostrar la foto de una mujer simplemente como un objeto sexual en Facebook u otras redes sociales.

- Llenar el correo de alguien con contenido sexual;

-Conseguir fotos de una persona para chantajearla para aprovecharse sexualmente de ella;

-Difundir videos/fotos "sexis" de una mujer en internet sin su permiso;

-Enviar imágenes con contenido sexual de una persona sin su consentimiento;

-Engañar o chantajear a una persona utilizando material online para tener relaciones sexuales con ella, difundir fotos o vídeos de contenido erótico, pornográfico $\circ$ sexual, sin consentimiento.

\section{Económica} patrimonial

La que se dirige a ocasionar un menoscabo en los recursos económicos de la mujer, a través de la perturbación de la Posesión de sus bienes, sustracción,

destrucción, retención indebida de objetos, instrumentos de trabajo, bienes y derechos patrimoniales.
-Pedir a la pareja las claves de acceso de su correo electrónico u otras cuentas de internet;

-Controlar a la pareja en Facebook o Twitter;

-Conocer la contraseña de la pareja en las redes sociales para bloquear amistades; -Coger el móvil de la pareja para ver llamadas e inspeccionar;

-Obligar a la pareja a quitar fotos de amigos en Facebook 


\begin{tabular}{|c|c|c|c|}
\hline & & $\begin{array}{l}\text { o dejar de chatear con } \\
\text { alguien. }\end{array}$ \\
\hline & & $\begin{array}{l}\text { Simbólica } \\
\text { La que, a través de } \\
\text { patrones estereotipados, } \\
\text { mensajes o signos } \\
\text { transmita y reproduzca } \\
\text { dominación, } \\
\text { desigualdad y } \\
\text { discriminación en las } \\
\text { relaciones sociales, } \\
\text { naturalizando la } \\
\text { subordinación de la } \\
\text { mujer en la sociedad. }\end{array}$ & $\begin{array}{l}\text { - Transgredir los derechos } \\
\text { humanos y digitales de una } \\
\text { persona por su "ideología } \\
\text { feminista". }\end{array}$ \\
\hline
\end{tabular}

Fuente: elaboración a partir de los trabajos de DONOSO; RUBIO; VILÀ, 2018 y del INFORME INSTITUCIONAL PRODUCIDO POR EL OBSERVATORIO DE DERECHOS EN INTERNET.

sociedad, y de los comportamientos y ejercicios discriminatorios y violentos en sus múltiples manifestaciones" (INFORME institucionAL, 2019, p.4).

Cuando se aborda la violencia en línea desde la perspectiva de género, "los estudios se centran en realizar segregaciones para diferenciar conductas de agresión o victimización según el sexo, o en la óptica de las relaciones afectivas. En ambos casos, los resultados de las investigaciones sitúan a las mujeres en una posición de vulnerabilidad frente a los hombres" (DONOsO; RUBIO; VILÀ, 2018, p.111). Aunque, no ha quedado claro ni concluyente, "lo que se pretende medir, quiénes son los actores principales o qué papel juega la socialización offline en los distintos tipos de conflicto" (MúÑ̃z; CUEsTA, 2015, p.106).

A continuación, se presenta la siguiente tabla sobre los tipos de violencia, modalidades y conductas según la literatura de violencia de género en espacios virtuales.

Algunas de las conductas señaladas en la tabla, se encuentran tipificadas como delitos informáticos en los diferentes ordenamientos jurídicos de los 
países, y al mismo tiempo, están vinculadas con la perspectiva de género, con el interés superior de los niñas, niños y adolescentes, así como el enfoque de los derechos humanos, por ejemplo, de acuerdo al INFORME INSTITUCIONAL PRODUCIDO POR EL OBSERVATORIO DE DERECHOS EN INTERNET, 2019, podemos encontrar los siguientes delitos:

a) Grooming: entendida como la acción deliberada de un adulto de contactar a una persona menor de edad, a través de medios electrónicos y cualquier otra tecnología de transmisión de datos, con el objeto de ganar su confianza y cometer un delito contra la integridad sexual de la misma. Se suelen detectar tres fases propias de este delito: primero, el contacto y acercamiento a través del vínculo de amistad; segundo, el acosador se vale de herramientas para mentir sobre su persona al entrar en contacto con el/la menor, buscando generar confianza y empatía; y el tercero, el componente sexual, el acosador consigue que el/la menor le envíe alguna fotografía o video con componentes sexuales o eróticos.

b) Ciberacoso / acoso digital: conductas de contenido sexual efectuadas a través de medios electrónicos con el objeto de amenazar o molestar a otra/s persona/s. Se manifiesta a través de comentarios sexuales; fotografías y grabaciones no consentidas; acoso a familiares y amigos; envío de gran cantidad de mensajes al día; monitoreo de redes sociales por medio de software malicioso y presión para conocer las contraseñas.

c) Sextorsión: es un tipo de chantaje a través del cual se amenaza a la persona destinataria con revelar información íntima de carácter sexual, a cambio de nuevo material, dinero u algún otro requerimiento. La extorsión puede provenir de la persona con la cual se compartió el material o bien, de una tercera, producto de un acceso ilegítimo a dicha información.

d) Ciberbullying: publicación de textos, imágenes, videos y/o audios a través de medios electrónicos, como mensajería instantánea, redes sociales, juegos en línea, utilizada para agredir y/o humillar a alguien. Usualmente, se da entre pares de un grupo.

e) Sexting: es un término inglés conformado por la unión de dos palabras: sex (contenido sexual) y texting (textear/ enviar mensajes). Se refiere al 
envío de imágenes y/o videos de contenido sexual a otra/s persona/s a través de distintos servicios de mensajería, usualmente por medio de dispositivos móviles. Si bien para la concreción de la conducta debe haber por lo menos dos personas (emisor y receptor), la eventual y posterior circulación de dicho material puede derivar en su publicación (en un sitio web, por ejemplo) o ser viralizada sin el consentimiento de su titular.

\section{Algunos datos sobre violencia de género en espacios digitales en México}

De acuerdo al Módulo de Ciberacoso (мосівA), 2019 del Inegi, el 23.9\% de la población de 12 años y más que utilizó internet en el 2019, fue víctima de ciberacoso en los últimos 12 meses. Esto equivale a 17.7 millones de personas de 12 años y más usuarias de internet a través de cualquier dispositivo del 2019 en México. Sobre los rangos de edad de ciberacoso, el 36.4\% de las mujeres de 20 a 29 años de edad que utilizaron internet en el 2019, fue víctima de ciberacoso en los últimos 12 meses. Por otro lado, el 40.3\% de las mujeres de 12 años y más víctimas de ciberacoso durante los últimos 12 meses recibió insinuaciones o propuesta sexuales. Finalmente, el 53.4\% de la población de 12 años y más que fue víctima de ciberacoso durante los últimos 12 meses, desconocía a la persona o personas que lo efectuaron. Estos datos muestran la existencia de la violencia de género en espacios virtuales en México, además de que el tipo de violencia que predomina es el sexual, y el desconocimiento de la identidad del agresor, que podría estar vinculado con el anonimato.

\section{Violencia de género en espacios digitales. Una mirada desde la pandemia de Covid-19 en México}

En marzo de 2020 la Organización Mundial de la Salud (oms) declaro formalmente como pandemia mundial al virus sARs-CoV2 (en lo subsecuente Covid-19), identificado por primera vez en diciembre del año 2019 en la región de Wuhan, China. La preocupación alcanzó niveles inusitados debido a la facilidad de contagio y propagación, situación que ha motivado profundos cambios en la manera en que se desarrollan las actividades cotidianas de las sociedades contemporáneas.

En su resolución 1/2020 de fecha 10 de abril del presente año, la Comisión 
Interamericana de Derechos Humanos estableció la excepcionalidad de la situación de emergencia que hoy vivimos. En dicha resolución destaca como la pandemia del Covid-19 puede afectar la plena vigencia de los derechos humanos de la población, en virtud de los serios riesgos para la vida, la salud, y la integridad personal como consecuencias directas del virus. Pero además destaca, los efectos a corto, mediano y largo plazo que tendrá en las sociedades modernas, y que se pueden vincular con los derechos económicos, sociales y culturales, así como con los derechos civiles y políticos de las personas, impacto que, no debemos olvidar, se da de forma reforzada sobre grupos en situación de vulnerabilidad. En este sentido, nos recuerda además que, América es una de las regiones más desiguales, con profundas brechas sociales, con problemas serios de pobreza y pobreza extrema, caracterizado además, por la precariedad o falta en el acceso al agua y el saneamiento, la inseguridad alimentaria, contaminación ambiental, falta de vivienda, informalidad laboral, entre otras, que hacen aún más preocupante el impacto socioeconómico del Covid-19, ya que todos estos elementos suponen ingredientes importantes para dificultar o impedir el acceso de millones de personas a las medidas de prevención contra la enfermedad (CIDH, 2020).

La pandemia ha traído consecuencias negativas en diversos sectores, y enfatizando desigualdades de género preexistentes en el acceso a servicios básicos, en las sobrecargas en labores de cuidado a las mujeres, pero, sobre todo, la actual crisis de Covid-19 pone en mayor riesgo de violencia a niñas y mujeres. El aislamiento social y la crisis sanitaria crean un escenario propicio para el aumento del riesgo de las mujeres y las niñas a padecer violencia y para un incremento en las tensiones al interior de los hogares. Una respuesta integral y coherente a la pandemia debe incluir la atención a la violencia contra las mujeres y las niñas como parte central de la estrategia, como parte de los servicios esenciales de salud y acceso a la justicia.

De acuerdo con el portal Animal Político (2020), durante la pandemia por Covid-19, algunos tipos de violencia contra la mujer- como la violencia familiar, los asesinatos y las llamadas de auxilio- se han intensificado. El total de mujeres asesinadas en abril de 2020 significó, en promedio, 11.2 mujeres asesinadas por día (la cifra mensual más alta registrada en lo que va del año). 
Además, de marzo a abril de 2020, los asesinatos de las mujeres aumentaron en un $2 \%$; mientras que los asesinatos de hombres se redujeron un $0.2 \%$. E1 hecho, de que, aún con la implementación de las medidas de distanciamiento social y confinamiento en casa los asesinatos de mujeres hayan aumentado, demuestra la persistencia de la crisis de violencia en México (Equis, 2020, p. 9) (Grafica 1).

Grafica 1: Tasa de mujeres víctima de violencia en México por mes.

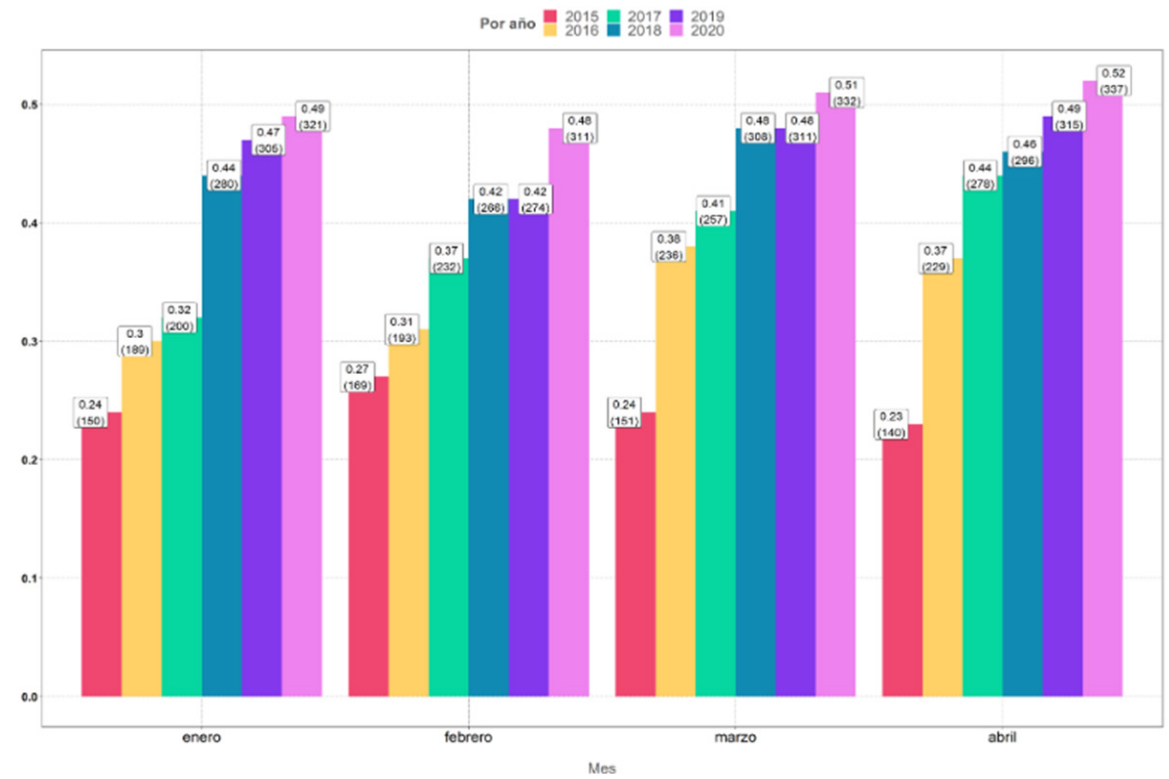

Fuente: Las Dos Pandemias, Equis, 2020.

Aunado a lo anterior, y de acuerdo con el estudio antes citado, la implementación de medidas de aislamiento produjo un incremento notable en las llamadas de auxilio relacionadas con violencia contra las mujeres. Por ejemplo, en el mes de abril se registraron un total de 103, 117 llamadas al 911 vinculadas con violencia sexual, familiar y contra las mujeres, lo que significó un 
promedio de 143 llamadas por hora. En el caso concreto de llamadas al 911 relacionadas con violencia contra la mujer, solo en el mes de abril de 2020, se registraron 21, 722 llamadas (30 en promedio por hora) (EQUIs, 2020, p. 11).

La contingencia sanitaria ha traído consigo consecuencias ominosas en materia de violencia de género, especialmente en el caso de las mujeres y niñas. A las desigualdades preexistentes, a la falta de acceso a bienes básicos, a los confinamientos, habría que sumar los problemas particulares que enfrentan las mujeres y niñas en contextos específicos o que pertenecen a grupos históricamente desaventajados. La pandemia ha disparado la violencia y es necesario tener información suficiente que sirva para generar políticas públicas que afronten efectivamente esta problemática.

\section{Hallazgos}

A partir de la literatura y evidencia empírica analizada sobre la violencia de género en espacios digitales y su vinculación con la situación de la pandemia Covid-19, se pueden señalar los siguientes elementos:

a) La violencia contra la mujer constituye así la forma más conocida de violencia basada en estructuras de género. Pero no es la única. Sin embargo, es aquella que eventualmente ha recibido la mayor atención por el proceso histórico, político y jurídico de reivindicación del derecho efectivo a la igualdad legal, social y cultural, además del reconocimiento en las relaciones y medios de producción y en la modificación de los roles incluyendo la crianza de los hijos y las labores del hogar.

b) La violencia cambia según la época, pues se utilizan herramientas y métodos que permiten hacerla más efectiva. $\mathrm{Al}$ igual que las otras perspectivas de violencia, las de género, se desarrollan con distintas tonalidades y se va transformando con los avances tecnológicos y las nuevas capacidades técnicas de los dispositivos o artefactos. Este nuevo fenómeno social llego para quedarse. Es parte de la vida cotidiana en la Era digital. Actualmente, los cibernautas encuentran en las distintas aplicaciones, en los múltiples artefactos y espacios de socialización, nuevas formas para agredir a otro sujeto, convirtiéndose así en un medio exponencial de violentar al otro desde el espacio virtual. 
c) Surgen nuevos actores visibles e invisibles (en razón del anonimato), además de nuevos procesos, tendencias, patrones, códigos, símbolos e interpretaciones.

d) El anonimato del agresor; la facilidad y la accesibilidad a la información a gran escala; la permanencia digital de los datos que subimos y los que producen los demás sobre nosotros; la facilidad de viralización y el poder de daño consecuente y trascendente, pueden favorecer el incremento y la multiplicación de la violencia de género en entornos digitales, aún más, constituir la violación de derechos humanos.

e) La violencia de género como fenómeno social, es compleja, multicausal, interdisciplinaria y multidisciplinaria, pero lo es aún más, en los espacios virtuales, pues implica un estudio transdisciplinario y la implementación de nuevas metodologías vinculadas con el desarrollo de la tecnología, información y de la vida cotidiana global y abierta.

f) Aunque existe una amplia literatura y estudios sobre la violencia de género en espacios virtuales (que se centran en realizar segregaciones para diferenciar conductas de agresión o victimización según el sexo, o en la óptica de las relaciones afectivas, con resultados que sitúan a las mujeres en una posición de vulnerabilidad frente a los hombres), no ha quedado claro ni concluyente, lo que se pretende medir, quiénes son los actores principales, la manera en que se produce la violencia o qué papel juega la socialización offline en los distintos tipos de conflicto.

g) No se puede desvincular, el análisis de la violencia en espacios digitales del enfoque de género de las políticas públicas, pues es responsabilidad del Estado, crear acciones y programas eficaces y eficientes para prevenir y combatirla, así como garantizar el cumplimiento de los derechos humanos.

h) Aunque en México existen importantes avances sobre la tipificación de delitos informáticos, no son concluyentes aquellos vinculados con violencia de género, aún menos con la creación de instancias y organismos dirigidos a la persecución de los mismos, tampoco la eficacia en la implementación de políticas públicas.

i) El factor contextual histórico, político, jurídico, social, cultural de 
México, influye en el desarrollo de la violencia de género y en los espacios digitales.

j) Puede haber una relación entre el confinamiento, la violencia de género es espacios virtuales y derechos humanos.

\section{Conclusiones}

La violencia de género en espacios digitales es un fenómeno social, complejo, multicausal y transdiciplinario, que necesita de nuevas metodologías vinculadas con los avances de la tecnología, información y conocimiento, así como de los nuevos enfoques de la vida cotidiana y global. Por otro lado, existen nuevos actores visibles e invisibles, nuevos procesos, tendencias, patrones, códigos, símbolos e interpretaciones.

No se puede desvincular, el análisis de la violencia en espacios digitales del enfoque de género de las políticas públicas, pues es responsabilidad del Estado, crear acciones y programas para prevenir y combatirla, así como garantizar el cumplimiento de los derechos humanos. Los gobiernos, deben crear estrategias eficientes y eficaces; construir políticas más equitativas que aseguren la paridad y/o equilibrio de género dentro y fuera de las instituciones; mejorar la focalización de los problemas públicos visibilizando las desigualdades e inequidades de género, finalmente, promover y crear los mecanismos y canales necesarios de comunicación para el desarrollo de la participación ciudadana, de la democracia, la modernización del Estado, la gobernanza y la gestión pública.

Aunque en México existen importantes avances sobre la tipificación de delitos informáticos, no es concluyente aquellos vinculados con la violencia de género, aún menos con la creación de instancias y organismos dirigidos a la persecución de los mismos, así como de la implementación de políticas públicas. De los pocos delitos que se denuncian, sólo una minoría se judicializa, sin que esto garantice de ningún modo llegar a obtener una sentencia. Además, una sentencia tampoco es una garantía de protección y justicia para las mujeres, pues de las pocas sentencias que se han podido analizar (debido a la falta de transparencia de sentencias por parte de los poderes judiciales) se han advertido violaciones al derecho de acceso a la justicia de las mujeres. Estas violaciones 
han sido motivadas por razones de género, donde quien juzga es quien genera, justifica y perpetúa la violencia y la discriminación hacia las mujeres.

La contingencia sanitaria ha traído consigo consecuencias ominosas en materia de violencia de género, especialmente en el caso de las mujeres y niñas. A las desigualdades preexistentes, a la falta de acceso a bienes básicos, a los confinamientos, habría que sumar los problemas particulares que enfrentan las mujeres y niñas en contextos específicos o que pertenecen a grupos históricamente desaventajados. La pandemia ha disparado la violencia y es necesario tener información suficiente que sirva para generar políticas públicas que afronten efectivamente esta problemática.

Finalmente, el factor contextual histórico, político, jurídico, social, cultural de México, influye en el desarrollo de la violencia de género y en los espacios digitales. En México, la violencia ha sido uno de los mecanismos para la "reivindicación y reconocimiento de derechos humanos", o al menos para el ordenamiento del sistema político a lo largo de su historia, también ha sido víctima de la impunidad y la corrupción, donde cada vez más se incrementa la inseguridad, las desapariciones forzadas y los feminicidios (sin contar a la cifras negras y dorada). El machismo y la misoginia, culturalmente arraigados en la sociedad y las instituciones, se configuraron como elementos de opresión hacia la mujer, la cual ha sido históricamente sometida a soportar la violencia como un destino. Aún más, en las últimas décadas, se ha agudizado las crisis económicas, políticas, sociales, culturales y de derechos humanos en el país y en tiempos de pandemia como el Covid-19, sólo se ha visibilizado aquello que ha existido siempre: la poca claridad respecto a la garantía del derecho a una vida libre de violencia.

\section{Referencias}

ADRIAN, Tamara. Visibilizando las formas invisibles de violencia de género. En STRAKA, Úrsula (Coord.). Violencia de Género. Universidad Católica Andrés Bello. Caracas. 2015. Disponible en: https://www.kas.de/c/document_library/ get_file?uuid=546068a2-e18a-7aac-0fcc-55b565e6d10f\&groupld=252038 
ANIMAL POLÍTICO. Cómo ha impactado el COVID en la violencia contra las mujeres y cuál es la respuesta institucional. 7 de agosto de 2020. Disponible en: https://www.animalpolitico.com/2020/08/ pandemia-violencia-contra-mujeres-respuesta-institucional/

ANSOLABEHERE, Karina y VALLE, Paula. Sociología de los Derechos Humanos. Serie de Guías de Estudio de la Maestría en Derechos Humanos y Democracia, Facultad Latinoamericana de Ciencias Sociales. México. 2017.

CHÍPULI, Arturo. Los Derechos Humanos frente a la Pandemia. Officium luris. Revista digital del Colegio de Doctores en Derecho del Estado de Veracruz, México. 2020. Disponible en_ https://www.researchgate.net/ publication/342154316_Los_derechos_humanos_frente_a_la_pandemia

CÁMARA DE DIPUTADOS. LIX LEGISLATURA. Comisión Especial para Conocer y dar Seguimiento a las Investigaciones Relacionadas con los Feminicidios en la República Mexicana y a la Procuración de Justicia Vinculada, Por la Vida y la Libertad de las Mujeres. Primer Informe Sustantivo de Actividades, México, Abril 2004- Abril 2005, Disponible en: http://132.247.1.49/mujeres/menu_superior/Feminicidio/2_ Info_nac/12.pdf.

COMISIÓN INTERAMERICANA DE DERECHOS HUMANOS (CIDH). Resolución 1/2020: Pandemia y Derechos Humanos en las Américas. Adoptada el 10 de abril de 2020. Disponible en: https://www.oas.org/es/cidh/decisiones/pdf/Resolucion1-20-es.pdf

DECRETO DEL EJECUTIVO DEL ESTADO, que se establece la medida temporal Hoy No Circula como acciones de prevención y de combate de los daños a la salud publicado el 8 de mayo de 2020 por el Periódico Oficial del Estado de Puebla. Disponible en http://periodicooficial.puebla.gob.mx/media/k2/attachments/ T_1_08052020_C.pdf

DONOSO, Trinidad; RUBIO, M. José; VILÀ, Ruth. La adolescencia ante la violencia de género 2.0: concepciones, conductas y experiencias. Educación XX1 Universidad Nacional de Educación a Distancia, 21 (1), p.109-133, 2018. Disponible en: http:// 
revistas.uned.es/index.php/educacionXX1/article/view/20180/16715.

EXPÓSITO, Francisca. Violencia de Género. Mente y Cerebro, 48, 20-25. México. 2011. Universidad Veracruzana. Disponible en: https://www.uv.mx/cendhiu/ files/2013/08/Articulo-Violencia-de-genero.pdf

EQUIS Justicia para las Mujeres. Violencia contra las mujeres e impunidad: ¿Más allá del punitivismo? EQUIS. México. 2019. Disponible en: https://equis.org.mx/ wp-content/uploads/2020/05/Informe_Impunidad_Y_Violencia.pdf

INCHÁUSTEGUI, Teresa (1999). “La institucionalización del enfoque de género en las políticas públicas. Apuntes en torno a sus alcances y restricciones", La Ventana, núm. 10, pp. 84-123. 1999.

FRAGOSO, Julia M. Feminicidio sexual serial en Ciudad Juárez: 1993-2001. Debate Feminista, México, Núm. 25, Abril 2002, disponible en: http://www.debatefeminista. cieg.unam.mx/wpcontent/uploads/2016/03/articulos/025_21.pdf.

FRIES, Lorena y LACRAMPETTE, Nicole. Feminismos, Género y Derecho. Derechos Humanos y Mujeres: Teoría y Práctica. Chile. Universidad de Chile, Facultad de Derecho, Centro de Derechos Humanos. Disponible en: https://libros.uchile.cl/365 INFORME INSTITUCIONAL PRODUCIDO POR EL OBSERVATORIO DE DERECHOS EN INTERNET. CENTRO DE PROTECCIÓN DE DATOS PERSONALES CENTRO DE CIBERSEGURIDAD DEL GOBIERNO DE LA CIUDAD DE BUENOS AIRES (BA-CSIRT). Violencia contra la mujer en el entorno digital. Conceptos, derechos y recomendaciones. Buenos Aires: Defensoría del Pueblo Ciudad Autónoma de Buenos Aires, 2019. Disponible en: http://cpdp.defensoria.org.ar/wp-content/ uploads/sites/5/2019/03/Violencia-contra-la-mujer-Cuadernillo.pdf.

LAGARDE, M., "Del feminicidio al feminicidio", Desde el jardín de Freud. Revista de Psicoanálisis, Colombia, n. 6, 2006, disponible en: http://revistas.unal.edu.co/ index.php/jardin/article/view/8343/8987.

LAMAS, Martha. El enfoque de género en las políticas públicas, México, Mimeo. Sin fecha. Disponible en: https://www.corteidh.or.cr/tablas/r23192.pdf MAFFIA, Diana. "Hacia un lenguaje inclusivo, ¿es posible?". Jornadas de actualización profesional sobre traducción, análisis del discurso, género y lenguaje inclusivo. 
Universidad de Belgrado. 2012. Disponible en: https://docplayer.es/86109700-Mesaredonda-hacia-un-lenguaje-inclusivo-es-posible.html

MÓDULO SOBRE CIBERACOSO 2019 (MOCIBA). Principales resultados. 2020. Disponible en:https://www.inegi.org.mx/contenidos/programas/mociba/2019/ doc/mociba2019_resultados.pdf

MUÑIZ, María; CUESTA Josefa. Violencia de género en entornos virtuales. Revista del Cisen Tramas/Maepova, 3, (2), 2015, 101-110, 2015. Disponible en: http://ppct. caicyt.gov.ar/index.php/cisen/article/view/7604. Consultado el 28 de agosto de 2020.

NACIONES UNIDAS. Estrategias de Nairobi orientadas hacia el futuro para el adelanto de la mujer, Nueva York, Departamento de Información Pública. ONU. New York. 1986. Disponible en: https://eige.europa.eu/library/resource/ IMIOC00003847c?lang=IV

PIETRAFESA, Andrea. Violencia de Género, Internet y el Derecho a la Libertad de Expresión: Un Nuevo Desafío Para el Derecho Internacional de los Derechos Humanos. American University International Law Review, 34 (5), 567-600. 2019. Disponible en https://digitalcommons.wcl.american.edu/cgi/viewcontent. cgi?article $=1983 \&$ context=auilr

POGGI, Francesca. Sobre el Concepto de Violencia de Género y su Relevancia para el Derecho. DOXA, Cuadernos de Filosofía del Derecho, 42, 285- 307. México. 2019. Disponible en: https://www.corteidh.or.cr/tablas/r6522.pdf

RAVELO, P. “La costumbre de matar: proliferación de la violencia en Ciudad Juárez, Chihuahua, México", Nueva Antropología, México, núm. 65, mayo-agosto de 2005. RICO, Nieves. Violencia de Género: Un Problema de Derechos Humanos. Serie Mujer y Desarrollo 6. CEPAL. 1996. Disponible en: https://www.cepal.org/mujer/ noticias/paginas/3/27403/violenciadegenero.pdf

Germina. 1 de Mayo de 2011. Disponible en: https://germina.cl/secciones/articulos/ genero-y-politicas-publicas-\%C2\%BFcamino-a-la-transversalizacion\#fnref-55-2

SCOTT, Joan W. 1990. El género: una categoría útil para el análisis histórico. AMELANG, James y NASH, Mary (eds.). Historia y género: las mujeres en la Europa moderna y contemporánea. Valencia, Edicions Alfons el Magnànim/Institució 
Valenciana d'Estudis i Investigació.

SUPREMA CORTE DE JUSTICIA DE LA NACIÓN (SCJN). Protocolo para juzgar con perspectiva de género. SCJN. México .2013. Disponible en: http://archivos. diputados.gob.mx/Comisiones_LXII/Igualdad_Genero/PROTOCOLO.pdf SUPREMA CORTE DE JUSTICIA DE LA NACIÓN (SCJN). Protocolo de actuación para quienes imparten justicia en casos que involucren la orientación sexual o la identidad de género. Suprema corte de justicia de la nación. SCJN. México. 2014. Disponible en: https://www.cndh.org.mx/sites/default/files/doc/Programas/VIH/ OtrasPublicacionesdeinteresrelacionadosconelVIH/SCJN/ProtocoloLGBT-SCJN.pdf

Recebido: $27 / 09 / 2020$

Aceito: $26 / 11 / 2020$ 